\title{
Ring Formation in the Smelting of Saprolite Ni-ore in a Rotary Kiln for Production of Ferro-nickel Alloy: Mechanism
}

\author{
Hitoshi TSUJI)* and Noboru TACHINO ${ }^{21}$ \\ 1) Previous Manufacturing Department, Nippon Yakin Kogyo Co., Ltd., Oheyama Works, 606-1 Shimoyamada, Yosano-cho, \\ Yoza-gun, Kyoto, 629-2302 Japan. \\ 2) Nippon Yakin Kogyo Co., Ltd., Oheyama Works, 413 Suzu, Miyazu, Kyoto, 629-2251
}

Japan. E-mail: noboru.tachino@nyk.jp

(Received on February 6, 2012; accepted on June 11, 2012)

\begin{abstract}
The clarification of mechanism of SR (Slag-Ring) formation in the smelting of saprolite Ni-ore by the rotary kiln has been successfully attempted. The walls in the kiln have a higher temperature than the raw materials, in particular, the point where the raw materials enter the bed have the highest temperature. In that point, the released low-MgO and high- $\mathrm{SiO}_{2} \cdot \mathrm{FeO}$ silicate accompanied by the recrystallization of nonstoichiometric serpentine are transformed to the primary melt, the fine parts of ores with much FeO and $\mathrm{Al}_{2} \mathrm{O}_{3}$ and limestone being melted by Ostwald ripening, which allows the formation of the secondary melt. Subsequently, its entrance into the bed leads to the cooling and precipitation on the wall and accretions, which allows the increase in the sticking force. The slight transportation of raw materials from the SR sticking zone toward the discharge end leads to the rapid decrease in the sticking. This is explained from the fact that the large growth of the particles by Ostwald ripening causes the reduction of melting amount into the melt, allowing the small precipitation on the wall and accretions. The resulting SR is locally formed. The fine parts of low-MgO and high-FeO type ore have higher concentration of point defects than that of the high-MgO and low-FeO type ore. This provides the lower melting point and higher diffusion rate to the former than the latter, which allows the former to have higher possibility of SR formation than the latter.
\end{abstract}

KEY WORDS: saprolite Ni-ore; rotary kiln; accretion; ring; SR (Slag-Ring); MR (Metal-Ring).

\section{Introduction}

Saprolite Ni-ore formed by the weathering in the tropics such as New Caledonia, Indonesia, Philippine is mainly composed of serpentine, being a silicate mineral contained around 1.8-2.4 and 8-20 mass \% of $\mathrm{Ni}$ and $\mathrm{Fe}$, respectively. That is generally smelted by the Elkem process to the ferronickel, which is mostly used as a nickel source for stainless steel. The calcination to around $1000^{\circ} \mathrm{C}$ by the rotary kiln provides drying and pre-reduction of ores, the calcinated product being subsequently charged into the electric furnace to be melt reduced. The slag and metal are tapped at around 1600 and $1400^{\circ} \mathrm{C}$, respectively. On the other hand, in "Nippon Yakin Oheyama Process,"1) which is the improved Krupp-Renn process, ${ }^{2)}$ Ni-ore is smelted with the semifused state at a maximum temperature of around $1400^{\circ} \mathrm{C}$ by the combustion heat of the pulverized coal burner and anthracite, the granular ferro-nickel, which is referred to as luppe with particle size $\geqq 0.1 \mathrm{~mm} \phi$ and average particle size around $1 \mathrm{~mm} \phi$, being produced. This smelting process has a great advantage of the small consumption of electric power energy whereas it has been to be pointed out for a long time that the formation of ring-shaped accretion on the

* Corresponding author

DOI: http://dx.doi.org/10.2355/isijinternational.52.1724 inside wall of the kiln cannot be avoided by any possibility, which causes serious trouble in the kiln operation. This is attributed to the liquid formation within the solid, which is an inevitably occurring phenomenon. A similar phenomenon has been reported in the cement kiln. ${ }^{3)}$

The two rings stick during smelting process on the inside wall of the kiln in Oheyama process. That rings include features as follows: 1) slag-ring (henceforth, SR); the raw materials are heated to around $1200-1250^{\circ} \mathrm{C}$, the liquid being formed within the solid to allow raw materials to begin to soften, which result in the sticking of SR on the wall. The SR diameter up to around $1.8 \mathrm{~m} \phi$, which has the open-area ratio $25 \%$ for the inner diameter of $3.2 \mathrm{~m} \phi$, play an important role for the suppression of the quick transportation of raw materials. However, the sticking is enhanced further, SR shrinking to around 1.4-1.6 $\mathrm{m} \phi$ (the open-area ratio $15-20 \%$ ) to result in the difficulty in the transportation of raw materials, which leads to the unstable operation and a lower performance of the rotary kiln. There is finally no other way than taking the kiln out of operation; 2) metalring (henceforth, MR); the fine reduced metal contained a high $\mathrm{C}$ melt, thus sticking on the wall in the ring-shape. The factors similar to the SR are also included. In particular, it seems that the grain size and $\mathrm{C}$ content of metal are closely involved in MR. The increase in the amount of sticking obstructs the transportation of raw materials as well as SR. 
However, a smaller amount of metal than slag and the sticking in a high temperature zone $\left(1300-1400^{\circ} \mathrm{C}\right)$ allows $\mathrm{MR}$ not to shrink seriously, but the non-regular melt-down operation of MR is must be performed with the reducing of charge to the kiln. Here, the factors of the SR formation could be included as follows; 1) in terms of raw materials: the physicochemical characteristics of ore (e.g., Fe, $\mathrm{CaO}$, $\mathrm{Al}_{2} \mathrm{O}_{3}$, basicity $\mathrm{MgO} / \mathrm{SiO}_{2}$, the degree of the point defects formed during the weathering), the additions of anthracite (reducing agent) and limestone (flux), the ash of pulverized coal; 2) operation: the temperature of raw materials, charge rate, filling degree, residence time, hold-up (residence weight), rotational speed, gas flow rate, the height of dam. These are intertwined with each other, and thereby a very complicated behavior is shown.

$\mathrm{SR}$ is also formed in the smelting process of iron ore by the rotary kiln. For example, Miyakado ${ }^{4}$ have reported that the powders occur by the rolling action of the bed, allowing the low-melting compounds of the olivine-system to be formed, which causes the SR formation in $\mathrm{SL} / \mathrm{RN}^{5)}$ direct-reduction plants (6.0 m $\phi \times 70 \mathrm{~m} \mathrm{~L}$ ) at JFE Steel Corp., Fukuyama. Here, $\mathrm{SL} / \mathrm{RN}$ process has the air injection fans installed every around $10 \mathrm{~m}$ on the kiln shell along the axis, allowing the combustion of $\mathrm{CO}$ and $\mathrm{H}_{2}$ gas from the bed, which may enable the more precise control of the inside temperature of the kiln. In addition, Chatterjee ${ }^{6-9)}$ has carried out a continuous experiment with a pilot kiln of $1.25 \mathrm{~m}$ in diameter and $13 \mathrm{~m}$ in length in the Tata Iron and Steel Co. Ltd., and reported that SR formation is promoted by the fine parts of iron ore and coal, and the mildly reducing atmosphere. Furthermore, Schlebusch ${ }^{10)}$ has performed experiments in a batch type kiln of $0.8 \mathrm{~m}$ inside diameter and $0.82 \mathrm{~m}$ in length, and reported that sticking is quickened by the fine parts of raw materials and the small temperature difference of $\Delta t$ between raw materials and inside wall. In that case, SEM observation and the chemical analysis of accretions have been performed. However, the mechanism of SR formation has been not discussed in detail. Thus, the clarification of the mechanism of SR formation has been attempted by the analysis of SR sampled in the actual kiln.

\section{Experimental Details}

The piece of SR sampled in the actual kiln shown in Fig.

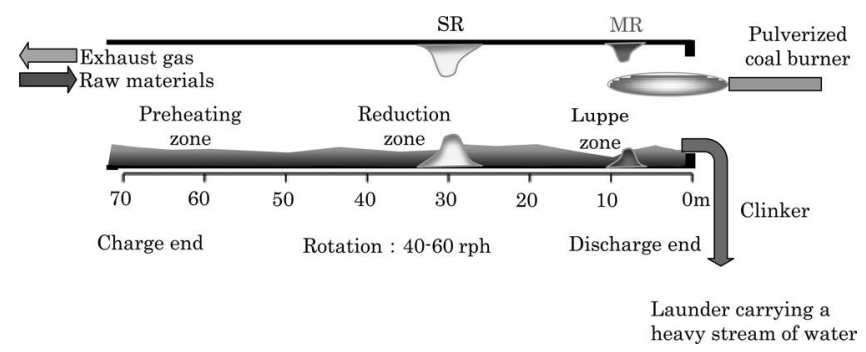

Fig. 1. Schematic diagram of the actual rotary kiln.
1 was embedded in resin and polished, and SEM-observation and EDS-analysis have been carried out with SHIMAZU SSX-550. ${ }^{11)}$ Further, chemical and XRD (SHIMAZU XRD$6100)$ analysis of sample ground to $-44 \mu \mathrm{m}$ have been performed.

\section{Experimental Results}

\subsection{Chemical Analysis of SR}

Table 1 shows the analysis value and the degree of $\mathrm{Ni}$ and Fe reduction of SR sampled in the actual kiln. The position of SR sticking is located in the almost middle of the reduction zone. Therefore, slag and metal have some $\mathrm{C}$ content of 2.02 and 1.00 mass\%, respectively. Furthermore, the degree of $\mathrm{Ni}$ and Fe reduction of 96.7 and 89.8 mass\%, respectively, indicates that reduction reaction in SR is almost completed.

\subsection{XRD of SR}

Then, Fig. 2 shows the diffraction pattern of SR. The diffraction peak of free-quartz at $2 \theta=28.0^{\circ}$ indicates that reaction with silicate has been yet completed. Furthermore, the strong diffraction peak at $2 \theta=30.9^{\circ}$ indicates a large amount of pyroxene $\left(\mathrm{MgO} \cdot \mathrm{SiO}_{2}\right)$, in contrast the weak at $2 \theta=35.8^{\circ}$ a small amount of olivine $\left(2 \mathrm{MgO} \cdot \mathrm{SiO}_{2}\right)$.

\subsection{SEM Observation of SR}

Figure 3 shows the SEM mapping. A large area of caves shows some considerable progress of slag formation. Moreover, Table 2 shows SEM quantitative analysis values. The SEM analysis value of metal is almost similar to that of the

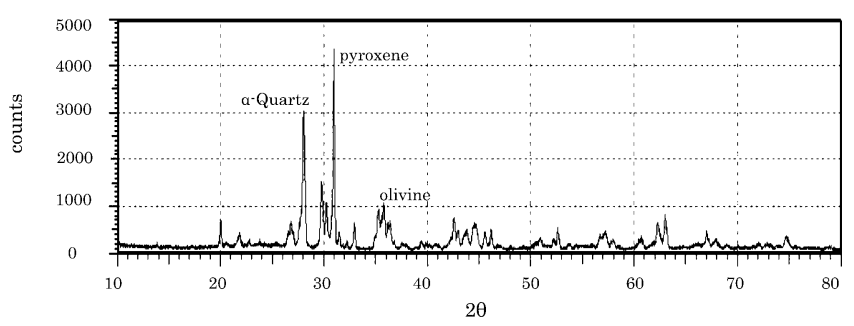

Fig. 2. XRD pattern of SR.

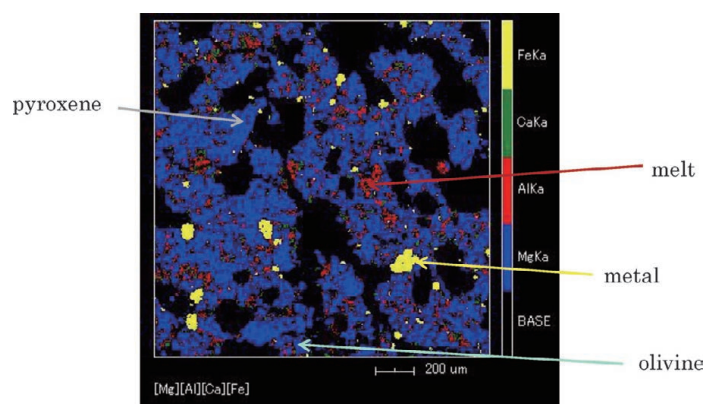

Fig. 3. SEM mapping of SR.

Table 1. Chemical analysis value of SR (mass\%).

\begin{tabular}{cccccccccccccc}
\hline & $\mathrm{C}$ & $\mathrm{SiO}_{2}$ & $\mathrm{Fe}$ & $\mathrm{M}-\mathrm{Fe}$ & $\mathrm{Fe}^{2+}$ & $\mathrm{Al}_{2} \mathrm{O}_{3}$ & $\mathrm{Ni}$ & $\mathrm{M}-\mathrm{Ni}$ & $\mathrm{CaO}$ & $\mathrm{MgO}$ & Weight ratio & $\begin{array}{c}\text { Degree of } \\
\text { reduction }\end{array}$ \\
\hline Slag & 2.02 & 52.36 & 8.19 & 6.11 & 1.46 & 3.19 & 1.39 & 1.24 & 4.17 & 26.35 & 81.9 & $\mathrm{Ni}$ & $\mathrm{Fe}$ \\
Metal & 1.00 & & 78.34 & & & & 16.55 & & & & 18.9 & 96.7 & 89.8 \\
\hline
\end{tabular}


Table 2. SEM quantitative analysis value of SR (mass\%).

\begin{tabular}{|c|c|c|c|c|c|c|c|c|}
\hline Metal & $\mathrm{Si}$ & $\mathrm{S}$ & $\mathrm{Cr}$ & $\mathrm{Mn}$ & $\mathrm{Fe}$ & $\mathrm{Ni}$ & & \\
\hline & 0.58 & 0.40 & 1.65 & 0.40 & 81.53 & 15.45 & & \\
\hline Slag & $\mathrm{MgO}$ & $\mathrm{Al}_{2} \mathrm{O}_{3}$ & $\mathrm{SiO}_{2}$ & $\mathrm{CaO}$ & $\mathrm{Cr}_{2} \mathrm{O}_{3}$ & $\mathrm{MnO}$ & $\mathrm{FeO}$ & $\mathrm{NiO}$ \\
\hline Olivine & 54.94 & 2.19 & 40.39 & 0.74 & 0.38 & 0.21 & 0.22 & 0.93 \\
\hline Pyroxene & 39.86 & 0.75 & 55.60 & 1.77 & 0.76 & 0.58 & 0.53 & 0.14 \\
\hline Melt* & 4.74 & 19.09 & 62.70 & 9.76 & 0.40 & 0.40 & 0.24 & 0.28 \\
\hline
\end{tabular}

chemical analysis. On the other hand, the slag phase is mainly composed of pyroxene and olivine, the composition of both minerals being approximately stoichiometric. Pyroxene has a very higher ratio than olivine as seen from XRD diffraction pattern in Fig. 2. $\mathrm{NiO}$ and $\mathrm{FeO}$ incorporated into these minerals are almost reduced. The high stability of Ni in olivine provides a higher $\mathrm{Ni}$ content in olivine than pyroxene. Then, the phase changes in the solidification process make the estimation of the melt composition difficult, even so, the composition of $\mathrm{Al}_{2} \mathrm{O}_{3}$ rich parts of melt are $\mathrm{MgO}=4.11, \mathrm{CaO}=9.78, \mathrm{Al}_{2} \mathrm{O}_{3}=20.03, \mathrm{SiO}_{2}=64.81 \mathrm{mass} \%$.

\section{Discussion}

\subsection{Sticking Location of SR}

SR sticks on the inside wall of the actual kiln, in where raw materials are transporting, at the limited zone A (i.e., around $20-30 \mathrm{~m}$ from the discharge end and the temperature of $1200-1250^{\circ} \mathrm{C}$ ) as shown in Fig. 4. The slight movement from point $\mathrm{A}$ to point $\mathrm{B}$ toward the discharge end leads to the rapid decrease in the amount of sticking. This allows the sticking of ring-shaped accretions. On the other hand, the flat coaching continuously sticks from point $B$ to around 10 m. In this respect, Chatterjee ${ }^{9)}$ has reported as follows; SR sticks at the point where $\mathrm{FeO}$ in the raw materials is stable and the lowest-melting point compounds occur. Even so, there is a large difference in the shape of raw materials concerned with the sticking phenomenon in the comparison between SR and coating. That is, in the back of SR, a large amount of powdery materials produced from briquettes destroyed by the rolling action of the bed exist, on the contrary in the coating zone powdery materials ${ }^{12)}$ cannot be almost found.

This seems to indicate that SR sticks at the point where powder begins to change to the nodule. Furthermore, the powdery materials contained much $\mathrm{FeO}$ and $\mathrm{Al}_{2} \mathrm{O}_{3}$ as shown in Table 3 have the high possibility of occurrence of the low-melting compounds. In particular, in the case of briquettes, the powdery materials formed by the rolling action of kiln accumulate in the bottom of bed, allowing the difficulty in being taken away as flue dust by the flow gas in the kiln, which causes that to seriously affect on the sticking. As for this, one reason is derived from the fact that the fine parts of low-MgO and high-FeO type ore, which is subject to stronger weathering, have higher concentration of point defects $^{11)}$ than that of the high-MgO and low-FeO type ore. Thus, the concentration of point defects in the silicate clearly controls the possibility of SR formation as well as the degree of $\mathrm{Ni}$ and $\mathrm{Fe}$ reduction. ${ }^{13)}$ Thus, a large amount of

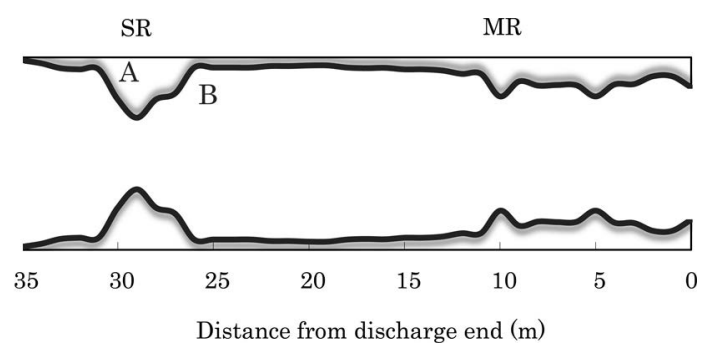

Fig. 4. Distribution of accretions in the actual kiln.

Table 3. Chemical analysis value and weight ratio of typical saprolite $\mathrm{Ni}$-ore in every grain size (mass\%).

\begin{tabular}{cccccccccc}
\hline \multirow{2}{*}{$\begin{array}{c}\text { Typical } \\
\text { saprolite Ni-ore }\end{array}$} & $\mathrm{SiO}_{2}$ & $\mathrm{Fe}$ & $\mathrm{Al}_{2} \mathrm{O}_{3}$ & $\mathrm{Ni}$ & $\mathrm{CaO}$ & $\mathrm{MgO}$ & \multicolumn{2}{c}{$\mathrm{M} / \mathrm{S}$} & Mass\% \\
\cline { 2 - 9 } & 38.87 & 12.65 & 1.22 & 2.45 & 0.13 & 24.16 & 0.622 & 100.0 \\
\hline+1 & 41.86 & 7.09 & 0.67 & 1.97 & 0.14 & 31.48 & 0.752 & 56.8 \\
& $1.00-0.50$ & 39.73 & 11.57 & 1.44 & 2.56 & 0.14 & 26.36 & 0.663 & 6.3 \\
& $0.50-0.25$ & 40.55 & 12.49 & 1.59 & 2.73 & 0.16 & 28.15 & 0.694 & 4.5 \\
$\begin{array}{c}\text { Screen } \\
(\mathrm{mm})\end{array}$ & $0.25-0.149$ & 39.40 & 15.24 & 1.76 & 2.89 & 0.20 & 23.11 & 0.587 & 4.9 \\
& $0.149-0.045$ & 40.53 & 16.55 & 1.85 & 2.71 & 0.21 & 22.20 & 0.548 & 8.4 \\
& $0.045-0.025$ & 34.88 & 19.00 & 1.76 & 2.48 & 0.28 & 17.44 & 0.500 & 3.6 \\
& -0.025 & 30.17 & 22.83 & 1.98 & 2.44 & 0.23 & 12.16 & 0.403 & 15.6 \\
\hline
\end{tabular}

melt occurs at the near SR sticking zone, whereas the melting down of raw materials cannot take place in the actual operation. This, therefore, seems to require the transformation of melt to solid.

\subsection{Melt Contained in SR}

Table 4 shows the compositions of $\mathrm{Al}_{2} \mathrm{O}_{3}$ rich parts of melt in the five SR samples. These are almost composed of $\mathrm{CaO}-\mathrm{Al}_{2} \mathrm{O}_{3}-\mathrm{SiO}_{2}$ ternary system, and the average and the standard deviation of the mole ratio $\left(\mathrm{Al}_{2} \mathrm{O}_{3} / \mathrm{CaO}\right)$ are 1.07 and 0.07 , respectively. This indicates that the phase of $\mathrm{Al}_{2} \mathrm{O}_{3}$ rich parts are a eutectic mixture of anorthite $\left(\mathrm{CaO} \cdot \mathrm{Al}_{2} \mathrm{O}_{3} \cdot 2 \mathrm{SiO}_{2} ; \mathrm{mp}: 1552^{\circ} \mathrm{C}\right)$ and $\mathrm{SiO}_{2}$. That phase corresponds to a point near the point $\mathrm{C}$ in the anorthite- $\mathrm{FeO}-$ $\mathrm{SiO}_{2}$ phase diagram shown in Fig. 5. ${ }^{14)}$ Then, it seems that these melt phases are formed in this order; 1) the release of low- $\mathrm{MgO}$ and high- $\mathrm{SiO}_{2} \cdot \mathrm{FeO}$ silicate ${ }^{11)}$ is accompanied by the recrystallization of non-stoichiometric serpentine, these transforming to the primary melt; 2) the fine parts of ores containing high content of $\mathrm{FeO}$ and $\mathrm{Al}_{2} \mathrm{O}_{3}$ as shown in Table 3 and that of limestone melt into the primary melt, secondary melt being formed; 3 ) the eutectic mixture of anorthite and $\mathrm{SiO}_{2}$ with a small amount of $\mathrm{MgO}$ and $\mathrm{FeO}$ is precipitated from the melt in the solidification processes. From stated above, it is estimated that the secondary melt probably has a composition that a small amount of $\mathrm{MgO}$ is melted into the melt near the ternary eutectic anorthite- $\mathrm{SiO}_{2}-\mathrm{FeO}$ point $\mathrm{D}$ in Fig. 5. SEM quantitative analysis values of $\mathrm{FeO}$ in $\mathrm{Al}_{2} \mathrm{O}_{3}$ rich parts of melt shown in Table 4 have the lower content than that of near the point D. However, taking into account the reduction after the solidification, the secondary melt may have the content of $\mathrm{FeO}$ near the point $\mathrm{D}$.

\subsection{Source of the Melt in SR}

Chatterjee ${ }^{7-9)}$ considered the ash of coal as the source of 
Table 4. SEM quantitative analysis value of $\mathrm{Al}_{2} \mathrm{O}_{3}$ rich parts of melt in SR (mass\%).

\begin{tabular}{crrrrrr}
\hline No. & \multicolumn{1}{c}{1} & \multicolumn{1}{c}{2} & \multicolumn{1}{c}{3} & \multicolumn{1}{c}{4} & \multicolumn{1}{c}{5} & \multicolumn{1}{c}{$\mathrm{Av}$} \\
\hline $\mathrm{MgO}$ & 3.00 & 6.78 & 0.08 & 1.16 & 4.11 & 3.03 \\
$\mathrm{Al}_{2} \mathrm{O}_{3}$ & 24.62 & 24.06 & 13.45 & 19.03 & 20.03 & 20.24 \\
$\mathrm{SiO}_{2}$ & 56.68 & 55.24 & 76.95 & 58.35 & 64.81 & 62.41 \\
$\mathrm{CaO}$ & 11.68 & 13.18 & 7.01 & 10.43 & 9.78 & 10.42 \\
$\mathrm{Cr}_{2} \mathrm{O}_{3}$ & 0.20 & 0.40 & 0.75 & 0.00 & 0.29 & 0.33 \\
$\mathrm{MnO}$ & 0.00 & 0.00 & 0.06 & 0.00 & 0.23 & 0.06 \\
$\mathrm{FeO}$ & 3.49 & 0.11 & 1.15 & 11.03 & 0.33 & 3.22 \\
$\mathrm{NiO}$ & 0.33 & 0.23 & 0.54 & 0.00 & 0.42 & 0.30
\end{tabular}

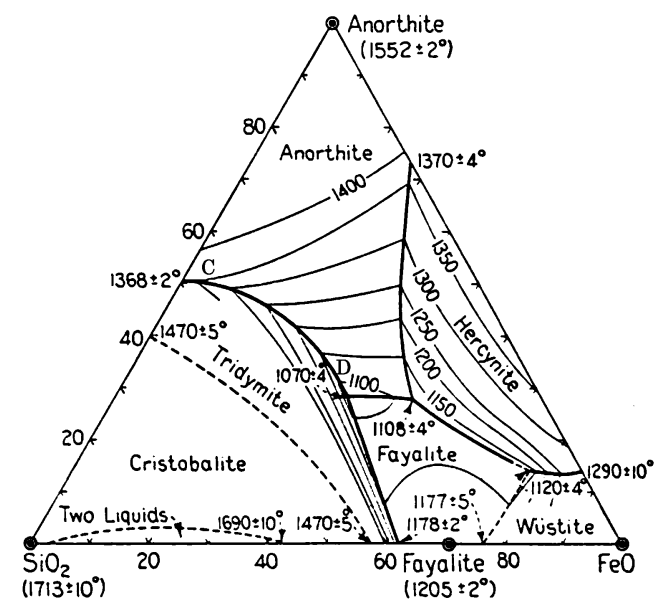

Fig. 5. Phase diagram of (anorthite $\mathrm{CaO} \cdot \mathrm{Al}_{2} \mathrm{O}_{3} .2 \mathrm{SiO}_{2}$ )-FeO- $\mathrm{SiO}_{2}$ (temperature: ${ }^{\circ} \mathrm{C}$ ).

Table 5. Chemical analysis value of ash in the anthracite and pulverized coal and weight ratio (mass\%).

\begin{tabular}{cccccccccc}
\hline Brand & $\mathrm{SiO}_{2}$ & $\mathrm{Fe}$ & $\mathrm{Al}_{2} \mathrm{O}_{3}$ & $\mathrm{CaO}$ & $\mathrm{MgO}$ & $\mathrm{Na}_{2} \mathrm{O}$ & $\mathrm{K}_{2} \mathrm{O}$ & $\begin{array}{c}\text { Weight } \\
\text { ratio }\end{array}$ \\
\hline Anthracite & 45.7 & 5.7 & 15.2 & 19.0 & 2.1 & 0.9 & 2.2 & 15.0 \\
Pulverized coal & 48.5 & 10.6 & 21.0 & 9.1 & 2.9 & 0.4 & 1.6 & 6.0 \\
\hline
\end{tabular}

the melt because $\mathrm{SiO}_{2}, \mathrm{Al}_{2} \mathrm{O}_{3}$ and $\mathrm{CaO}$ are the main compositions of SR. In the Ni smelting, the composition of ash is a mixture of anorthite and $\mathrm{SiO}_{2}$, extremely close to the composition of $\mathrm{Al}_{2} \mathrm{O}_{3}$ rich parts of melt in $\mathrm{SR}$ as shown in Table 5. However, ash seems to have not significant effect on the SR formation from the following; 1 ) the amount of $\mathrm{CaO}$ and $\mathrm{Al}_{2} \mathrm{O}_{3}$ contained in the ash formed from the combustion of anthracite and pulverized coal is lower than that in ore by about one order of magnitude; 2) the combustion of anthracite just begins from near the SR sticking zone; 3) SR also sticks by the using heavy fuel oil burner; 4) SR often sticks at the time of changing the ore blend.

\subsection{Mechanism of SR Formation}

Chatterjee $^{8)}$ has reported that SR is formed by the gravitational force and kiln rotation because that grows toward the central axis of the kiln. However, it is clear that the very short transportation distance toward the discharge end give the rapidly decrease in the amount of sticking, the resulting

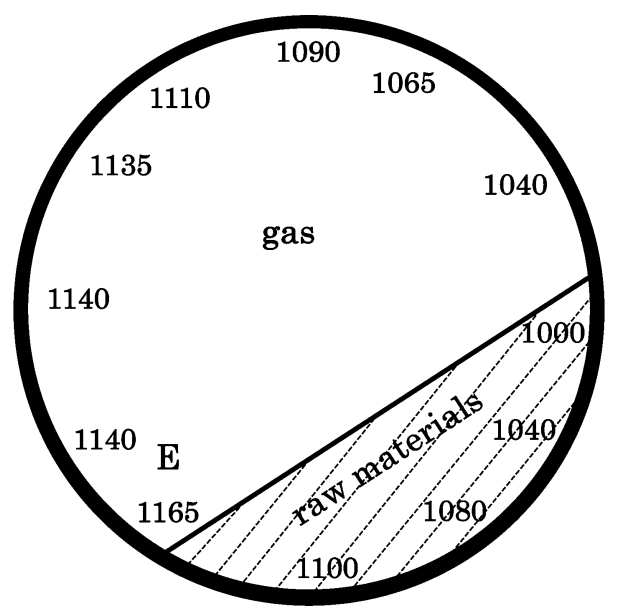

Fig. 6. Distribution of wall temperature $\left({ }^{\circ} \mathrm{C}\right)$ in the reduction zone (according to Schnabel).

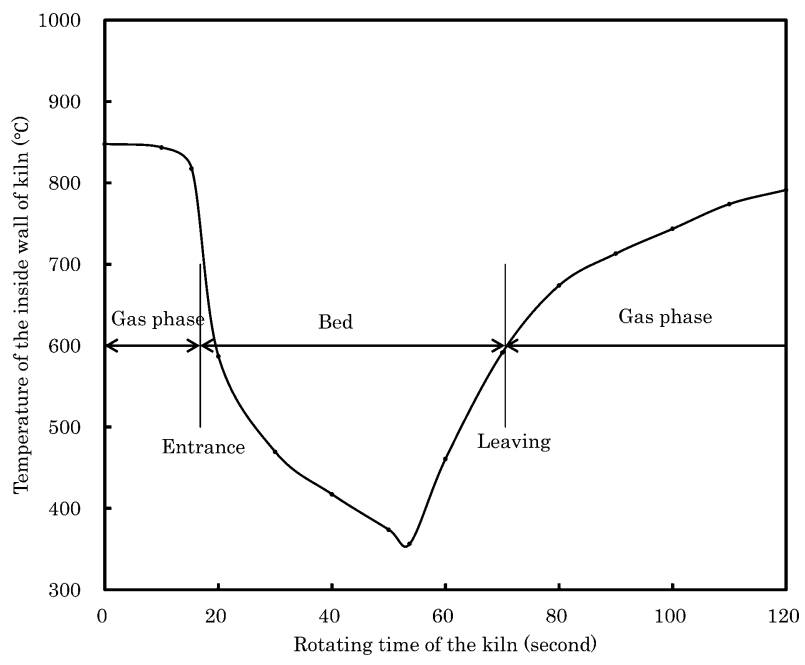

Fig. 7. Relation between temperature of inside wall of kiln and position (according to Schnabel).

The process of SR formation

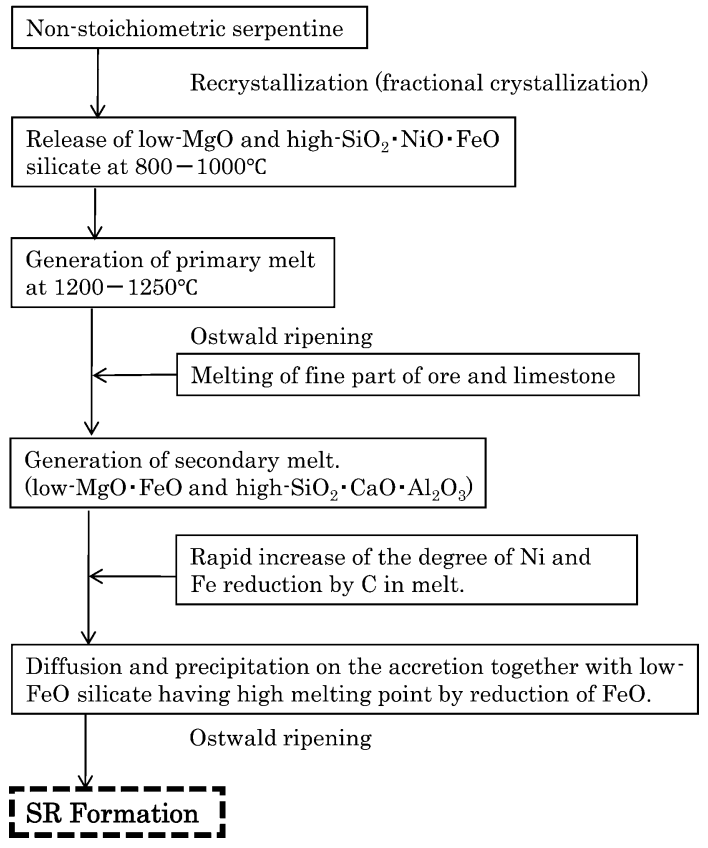

Fig. 8. Schematic representation of the process of SR formation. 


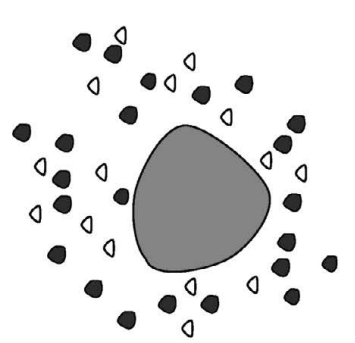

1) Solution of the fine particles to the primary melt.

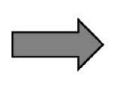

2) Formation of the secondary melt (low-MgO and high- $\mathrm{FeO} \cdot \mathrm{SiO}_{2} \cdot \mathrm{Al}_{2} \mathrm{O}_{3} \cdot \mathrm{CaO}$ ).

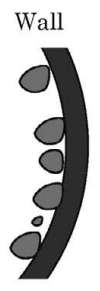

3) Precipitation on the wall.

Fine ore $\left(\mathrm{FeO}, \mathrm{Al}_{2} \mathrm{O}_{3}\right.$ rich)

0 Fine limestone

The primary melt accompanied with recrystallizaion of non-stoichiometric serpentine (low-MgO and high- $\mathrm{FeO} \cdot \mathrm{SiO}_{2}$ )

b) Formation of coating by the liquid phase sintering.

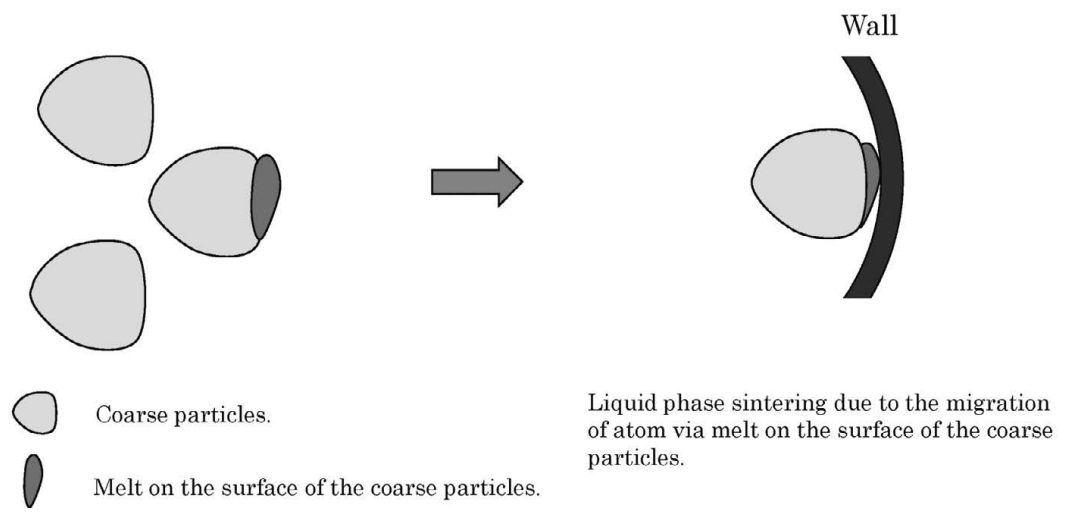

Fig. 9. Difference in the sticking mechanism between SR and coating.

SR is formed. Therefore, that concept seems to be unreasonable. In addition, Gorog ${ }^{3)}$ has reported that the particles with the melted surface coalesce with each other by the kiln rotation to grow into the nodules in the lime sludge kiln, and the particles stick on the wall by the same mechanism, thus SR being formed. However, it seems that the above concept allows the sticking to take place over long distances, which causes the ring-shaped accretions not to be formed. Generally, the kiln wall is subject to the convection and radiation heat-transfer from the gas and raw materials, which provides the kiln to have the characteristic that the temperature of wall is higher than that of raw materials. In particular, the distribution of temperature measured by Schnabel ${ }^{15)}$ in the reduction kiln demonstrates that the point $\mathrm{E}$ in Fig. 6 has the highest wall temperature among the exposed wall. Furthermore, Fig. 7 demonstrates that the entrance into the bed lead to the cooling of the wall.

Then, from the mentioned at section 4.2 , it is reasonable to explain the mechanism of SR formation by Ostwald ripening shown in Fig. 8 as follows; 1) the fine parts of ores containing high content of $\mathrm{FeO}$ and $\mathrm{Al}_{2} \mathrm{O}_{3}$ and that of limestone melt, for the reducing surface energy, into the melt existing on the surface of the raw materials which rolled down along the slope of bed surface and collided to the wall; 2) the precipitation takes place on the surface of wall and accretions corresponding to the coarse particles during the process that the raw materials enter the bed to be cooled. The repeating of melting and precipitation allows SR with the lamellar cross-sectional area to be formed involving the briquettes and reduced metals. Thus, in other words, the above stated characteristic of kiln favors the SR formation. Thereafter, the slight transportation of raw materials toward the discharge end leads to the rapid decrease in the amount of sticking. This is explained from the fact that the large growth of the particles by Ostwald ripening causes the reduction of amount of melting into the melt and precipitation on the wall and accretions. Moreover, it seems that the degree of Fe reduction proceeds in SR as shown in Table 1, allowing the melting point of the melt to increase, which causes the solidification to take place easily. On the other hand, few powdery materials are found in the coating zone. Thereby, the sticking does not take place by the Ostwald ripening but by the general liquid sintering. Here, Fig. 9 shows the difference in both the sticking phenomena.

\section{Conclusions}

The clarification of mechanism of SR formation has been attempted by the SEM-EDS, XRD and chemical analysis of SR sampled in the actual kiln. The following results are 
obtained.

(1) The walls in the kiln have a higher temperature than the raw materials, in particular, the point where the raw materials enter the bed has the highest temperature. In that point, the released low- $\mathrm{MgO}$ and high- $\mathrm{SiO}_{2} \cdot \mathrm{FeO}$ silicate accompanied by the recrystallization of non-stoichiometric serpentine are transformed to the primary melt, the fine parts of ores with much $\mathrm{FeO}$ and $\mathrm{Al}_{2} \mathrm{O}_{3}$ and limestone being melted by Ostwald ripening, which allows the formation of the secondary melt.

(2) The entrance of the secondary melt into the bed leads to the cooling and precipitation on the wall and accretions, which allows the increase in the sticking force.

(3) The slight transportation of raw materials toward the discharge end leads to the rapid decrease in the amount of sticking. This is explained from the fact that the large growth of the particles by Ostwald ripening causes the reduction of amount of melting into the melt, allowing the decrease in the precipitation on the wall and accretions. The resulting SR is locally formed. Thus the characteristic of fine particles and kiln favors the SR formation.

(4) The fine parts of low-MgO and high-FeO type ore have higher concentration of point defects than that of the high-MgO and low-FeO type ore. This provides the lower melting point and higher diffusion rate to the former than the latter, which allows the former to have higher possibility of SR formation than the latter.

(5) The secondary melt probably has a composition that a small amount of $\mathrm{MgO}$ is melted into the melt near the ternary eutectic anorthite- $\mathrm{SiO}_{2}-\mathrm{FeO}$ because; 1) the phase precipitated from the melt is the binary eutectic anorthite $\left(\mathrm{CaO} \cdot \mathrm{Al}_{2} \mathrm{O}_{3} \cdot 2 \mathrm{SiO}_{2}\right)-\mathrm{SiO}_{2}$ containing a small amount of
$\mathrm{MgO}$ and $\mathrm{FeO} ; 2) \mathrm{FeO}$ is reduced after the solidification.

(6) The ash of coal has some high content of $\mathrm{SiO}_{2}$, $\mathrm{Al}_{2} \mathrm{O}_{3}$ and $\mathrm{CaO}$ as well as the $\mathrm{Al}_{2} \mathrm{O}_{3}$ rich parts of melt in SR. However, ash seems to have not significant effect on the SR formation from the following reason; 1) the amount of $\mathrm{CaO}$ and $\mathrm{Al}_{2} \mathrm{O}_{3}$ contained in the ash formed by the combustion of anthracite and pulverized coal is lower than that in ore by about one order of magnitude; 2) SR also sticks by the using heavy fuel oil burner.

\section{REFERENCES}

1) T. Watanabe, S. Ono, H. Arai and T. Matsumori: Int. J. Miner. Procss, 19 (1987), 173.

2) F. Johannsen: Stahl Eisen, 34 (1934), 969.

3) J. P. Gorog: Lime Sludge Kiln Operation, Weyerhaeuser Technology Center, (2002), 15, http://faculty.washington.edu/malte/seminar/ Au04/LimeKilnOperations.pdf, (accessed December 3, 2011).

4) S. Miyakado, A. Honda, Y. Yamaoka, K. Yatunami, R. Yamamoto and K. Shiobara: NKK Steel Tech. Rep., 80 (1979), 34.

5) L. Bogdandy and H. J. Engell: The Reduction of Iron Ores, SpringerVerlag, New York, (1971), 306.

6) A. Chatterjee, B. D. Pandey, C. C. Ojha, M. Tiwary, M. N. Poddar and P. K. Chakravarty: SEAISI Q., Oct., (1978), 64.

7) C. C. Ojha and A. Chatterjee: Trans. Indian Inst. Met., 32 (1979), 101.

8) A. Chatterjee and B. D. Pandey: Ironmaking Steelmaking, 6 (1981), 250 .

9) A. Chatterjee and P. K. Mukhopadhyay: Metall. Trans. B, 14B (1983), 393

10) D. W. Schlebusch: Dissertation, The University of RWTH, Aachen, Germany, (1978).

11) H. Tsuji: ISIJ Int., 52 (2012), 333

12) A. L. Morrison, J. K. Wright and K. McG. Bowling: Ironmaking Steelmaking, 1 (1978), 32

13) H. Tsuji: ISIJ Int., 52 (2012), 1000.

14) Phase Diagrams for Ceramists, The American Ceramic Society, Columbus, OH, (1964), 288.

15) W. Schnabel: Dissertation, The University of RWTH, Aachen, Germany, (1977). 